\title{
Do computer games enhance learning about conflicts? A cross-national inquiry into proximate and distant scenarios in Global Conflicts
}

\author{
Ronit Kampf ${ }^{\mathrm{a}, *}$, Esra Cuhadar ${ }^{\mathrm{b}}$ \\ ${ }^{a}$ Department of Communication and Program in Youth and Child Culture, Tel Aviv University, 06995, Tel Aviv, Israel \\ ${ }^{\mathrm{b}}$ Department of Political Science, Bilkent University, Bilkent, Ankara 06800, Turkey
}

\section{A R T I C L E I N F O}

\section{Article history:}

Available online 16 September 2014

\section{Keywords:}

Global Conflicts

Israeli-Palestinian conflict

Guatemalan civil war

Active learning

Knowledge acquisition from games

Attitude change

\begin{abstract}
A B S T R A C T
Interactive conflict resolution and peace education have developed as two major lines of practice to tackle intractable inter-group conflicts. Recently, new media technologies such as social media, computer games, and online dialogue are added to the existing set of tools used for peace education. However, a debate is emerging as to how effective they are in motivating learning and teaching skills required for peace building. We take issue with this question and have conducted a study investigating the effect of different conflict contexts on student learning. We have designed a cross-national experimental study with Israeli-Jewish, Palestinian, and Guatemalan undergraduate students using the Israeli-Palestinian and Guatemalan scenarios in the computer game called "Global Conflicts." The learning effects of these scenarios were systematically analyzed using pre- and post-test questionnaires. The study indicated that Israeli-Jews and Palestinians acquired more knowledge from the Guatemalan game than Guatemalans acquired from the Israeli-Palestinian game. All participants acquired knowledge about proximate conflicts after playing games about these scenarios, and there were insignificant differences between the three national groups. Israeli-Jews and Palestinians playing the Israeli-Palestinian game changed their attitudes about this conflict, while Guatemalans playing the Guatemalan game did not change their attitudes about this case. All participants changed their attitudes about distant conflicts after playing games about these scenarios.
\end{abstract}

(c) 2014 Elsevier Ltd. All rights reserved.

\section{Introduction}

Intractable inter-group conflicts are among the most challenging types of conflicts. These conflicts are highly resistant to resolution, pervasive, destructive, involve well-entrenched hostile perceptions of the out-group, drag on for an extended period of time, and are prone to escalation over and over again (Bar-Tal, 2013; Coleman, 2000; Kriesberg, Northrup, \& Thorson, 1989). In such conflicts, changing the hostile attitudes and behaviors of people essential to transform the conflict. Hostile attitudes and enemy images are passed on from one generation to another with the learning of the conflict narratives embedded in various socialization agents. Conflict narratives often promote an ethnocentric view of the past or present events and parties hardly communicate with each other directly (Bar-Tal, 1997). Tackling these attitudes and narratives are especially important because not only peace requires more than peace agreements (Saunders, 1999), but also because people are involved with some of the critical political decisions.

\footnotetext{
* Corresponding author.
}

Conflict resolution and political psychology disciplines have developed a number of theories and practical tools in order to change attitudes and reframe conflict narratives to resolve conflicts. ${ }^{1}$ Among many approaches that are available to practitioners, two have extensively been applied: (a) interactive conflict resolution (ICR) (Fisher, 1997) or interactive problem-solving workshops (Kelman, 1995) and (b) peace education (PE) (Salomon, 2002). ICR workshops have been applied to many inter-group conflicts with different levels of participants ranging from grassroots to high level influentials for several decades now (Cuhadar \& Dayton, 2011; Fisher, 2005). ${ }^{2}$ Both ICR and PE often have the goals of reducing inter-group prejudice and negative stereotyping, promoting

\footnotetext{
${ }^{1}$ For an extensive review of existing theories of change in conflict resolution see Anderson, Chigas, and Woodrow (2007).

2 ICR refers to interactive dialogue workshops where members of adversarial groups are brought together repeatedly often with the help of a third party facilitator (Fisher, 1997). The goal is to provide a safe, off-the-record venue for dialogue; to increase communication, understanding and trust among polarized groups; breakdown the stereotypes and dehumanizing cognitions that permit the partisans to wage the conflict destructively; and to develop consensus-based proposals that can be transferred to the negotiations or public opinion (Fisher, 1997).
} 
inter-group empathy and understanding, building trust, and creating awareness about the root causes of conflict and about non-violence. Promoting and facilitating inter-group contact and educating the participants on various aspects of conflicts and peace-building are among the common activities used in PE initiatives in order to attain these goals.

The prevalence of internet in the last two decades has added a new dimension to ICR and PE activities and provided a new set of tools targeting the reduction of inter-group conflict. Computer chat rooms, social media, and web based role-play games began to be used as another potential venue to bring members of adversarial groups together in conflict environments. These new tools can be an alternative medium to accomplish the goals of peace education, as articulated by Salomon (2002). With the help of computer mediated forums and games perhaps people can learn to legitimate the other's collective narrative and see events from both lenses; can critically examine their in-group's contribution to the conflict and challenge their perception of sole victimhood; and perhaps develop empathy in order to appreciate other's pain and loss and generate mutual humanization.

Are new media technologies as effective as traditional approaches to peace education? Can they help acquire and enhance knowledge about the conflict? Can they engender perspective taking and attitude change? Is it possible to achieve individual change towards the conflict and the out-group without social contact with members of this group?

In this paper, we tackle these questions by focusing on the assessment of a computer game titled Global Conflicts in order to identify the effects it might have on enhancing knowledge about the conflict and the parties in conflict as well as generating attitude change and perspective taking. Global Conflicts is a computer game designed to educate students about conflicts and help them acquire skills such as inquiring about different conflict contexts and writing journalistic reports geared towards a specific audience. Our study has two main purposes: To what extent computer-based simulations enhance students' knowledge and perspective taking about conflicts and whether these learning effects differ for different populations (those who are direct parties to the conflict and those who are not) and different conflict types and contexts (Israeli-Palestinian and Guatemalan).

Using Global Conflicts, we conducted an experimental study among Israeli-Jewish, Palestinian, and Guatemalan undergraduate students. The game was used for educational purposes in a classroom setting. Each student played in random order two scenarios of the game in the role of a journalist: First scenario was related to the Guatemalan civil war and the second one was related to a situation at the Israeli-Palestinian checkpoint. Our purpose was to understand how effective the game in general was as a pedagogical tool in teaching about conflicts especially with regard to knowledge acquisition, attitude change and perspective taking as a crucial skill in conflict resolution. In particular, we were interested in finding out whether the two different game scenarios made any differences in terms of learning outcomes. Do students learn differently when they engage in a computer game about conflicts that are geopolitically proximate (i.e. a conflict they experience first hand, thus hold stronger attitudes towards) or when the conflict is geopolitically distant (i.e. conflict not experienced first hand, thus hold weaker attitudes towards)?

We measure the following outcomes in this study: (1) whether playing the game enhances the level of knowledge among the students about the particular conflict; (2) whether playing the game contributes to attitude change and the development of perspective taking which is a crucial conflict analysis skill; (3) whether learning about the conflict has changed from one national group to the other especially when the conflict context varied.

\section{Literature review}

ICR and PE are the two most common tools of conflict resolution which rely heavily on the "social contact" hypothesis. Social contact hypothesis argues that lack of contact between groups promotes bias and prejudice and may lead to its institutionalization over time. Once institutionalized, lack of contact reinforces negative attitudes and beliefs about the out-group, further solidifying the boundaries between the in-group and the out-group (Hewstone \& Greenland, 2000:140). As a remedy, the human relations movement advanced the theory that if lack of contact reinforces inter-group bias and prejudice, contact between the members of identity groups can be used to overcome it (Pettigrew, 1986). As members of identity groups interact, their preconceived notion of the other is challenged, commonalities across groups are revealed while accentuated differences are minimized, and members of each group humanize each other (Cuhadar \& Dayton, 2011 for an overview).

The practice of PE is diverse, however the major outcomes expected of PE initiatives are summarized by one of its pioneers, Salomon, as follows: (1) legitimation of the other's collective narrative in a way that events can be seen from both lenses; (2) critical examination of the in-group's contribution to the conflict in which the parties are liberated from competition for sole victimhood; (3) develop empathy for suffering in order to appreciate other's pain and loss and generate mutual humanization; and (4) engagement in non-violent activities (Salomon, 2002 cited in Hadjipavlou, 2007: 41). Although building empathy is mentioned as a standalone expected outcome by Salomon, it can be further argued that the first two outcomes also are closely related to and require the building of empathy and perspective taking. Therefore, empathy and perspective taking can be considered as one of the key expected outcomes of PE. Generating empathy and perspective taking was emphasized as the most critical element by many scholars in the conflict resolution literature (e.g. Kelman, 1997; Malhotra \& Liyanage, 2005; Maoz, 2000, 2004; Maoz \& Bar-On, 2002).

PE uses a variety of methods. While some of the initiatives may combine contact based activities with the teaching of a certain curriculum, some others do not incorporate contact with the members of the other group but rather focus on teaching participants conflict resolution skills, and a curriculum emphasizing human rights, diversity, co-existence, gender sensitivity, and non-violent action.

Both ICR and PE activities target attitude change at the individual level. In such activities, attitude change can take place through different mechanisms (Cuhadar \& Dayton, 2011: 279; Pettigrew, 1998: 70-73). The first mechanism is through new learning about the out-group. Attitude change may occur by generating new learning about the other that contradicts the existing stereotypes and attitudes. The second one is by changing behavior. This means by changing the behavior first, dissonance will be formed between the prejudiced attitude and the new positive behavior, which may result in the revision of the old attitude. The more repeated the contact is or the new information in varied settings, the more likely that the revision of attitudes in line with the new behavior will take place. The third is through generating affective ties, which refers to positive change by forming strong affective ties and empathy with the out-group, intimacy, and inter-group friendship. The last mechanism is through in-group reappraisal. In this one, attitude change occurs by learning and revising attitudes about the in-group. New learning about in-group (for example the learning that in-group is not homogenous or superior) leads to the reduction of in-group bias and favoritism and consequently leads to a "less provincial" view of out-group.

These four mechanisms described by Pettigrew are closely linked to the research exploring attitude change. Attitude change 
can occur through cognitive, affective, or behavioral processes and do not need to have all three at the same time (Eagly \& Chaiken, 1998:272). Until recently, research on attitude change has focused more on cognitive processes such as the link between attitude consistency and change (Eagly \& Chaiken, 1998). An important finding has been that people holding more extreme attitudes are more likely to resist change through social influence (Eagly \& Chaiken, 1998:287). When attitudes are linked to self-defining values and reference groups, which is often the case in intractable conflicts, they are very much resistant to change.

\subsection{Can the use of new media technologies be as effective in teaching about conflict and perspective taking?}

The prevalence of internet in the last two decades has added a new dimension to ICR and PE activities targeting the reduction of inter-group conflict by changing attitudes. Computer chat rooms, social media, and web based role-play games began to be used as another potential venue to bring members of adversarial groups together in conflict environments. Examples are growing in number. Online conflict resolution courses are now offered in a variety of academic institutions (Bhappu, Ebner, Kaufman, \& Welsh, 2009; Ebner, 2008; Matz \& Ebner, 2010). It has also become common that students are brought together in online facilitated dialogue using technology. E-negotiation and e-mediation systems are made available in order to help negotiators satisfy their requirements and to assist them in negotiations (Druckman, Druckman, \& Arai, 2004; Druckman et al., 2011; Lin, Gev, \& Kraus, 2011). Technology becomes prevalent in the use of decision support systems in negotiation simulations (Wilkenfeld, Young, Queen, \& Assal, 2005) and web based simulation programs like GlobalEd (Brown et al., 2003; Gehlbach et al., 2008).

Soliya is perhaps one of the most well-known examples of online dialogue which brings together young people from the US and various Middle Eastern countries for constructive dialogue with innovative use of new media technologies with the aim of changing the way societies resolve their conflicts (www.soliya.net). Another example is a dialogue group established by conflict management practitioner Arik Segal on Facebook which brings together Israeli and Palestinian young people virtually and facilitates dialogue. Several conflict resolution NGOs are using new media technologies in their activities. Among these are Search for Common Ground (who recently collaborate with Soliya), and the Peres Center for Peace, which uses PeaceMaker, a computer game simulating the Israeli-Palestinian conflict with the purpose of teaching Israeli and Palestinian young people how to reach two-state solution. In sum, new media technologies are becoming a significant addition to the traditional methods of ICR and PE, discussed above. They also make interaction easier when it is costly or impossible to bring a large number of parties together.

These new computer mediated tools can be an alternative to accomplish the goals of peace education as articulated by Salomon (2002). With the help of computer games perhaps people can learn to legitimate the other's collective narrative and see events from both lenses; can critically examine their in-group's contribution to the conflict and challenge their perception of sole victimhood; and perhaps develop empathy in order to appreciate other's pain and loss and generate mutual humanization. The production of special games in the recent years with this purpose is noteworthy. One well-known example is PeaceMaker, a computerized simulation of the Israeli-Palestinian conflict, produced by Impact Games and supported by the USIP (Burak, Keylor, \& Sweeney, 2005).

Yet, the assessment of the effectiveness of new media technologies in educating about peace and conflict is severely lacking. Are new media technologies as effective as traditional approaches to peace education? Can they help enhance knowledge about the conflict? Can they engender perspective taking and attitude change? Is it possible to achieve individual change towards the conflict and the out-group without social contact with members of this group?

Few studies focused on the evaluation of technology use for conflict resolution purposes. Most of the research on web-based and digital technologies in teaching and learning (e.g. Hannafin \& Kim, 2003; Lawless \& Brown, 2003) focus on innovations in using world wide web in teaching in general rather than focusing on computer games in a conflict resolution context. Few studies (Chalamish \& Kraus, 2012; Lin et al., 2011) systematically analyzed the effects of technology support as opposed to no technology support in negotiation simulations. Some argue that face-to-face negotiation has many advantages over e-negotiation, others think the opposite (Galin, Gross, \& Gosalker, 2007). In an experimental study comparing an e-mediator with live mediation, Druckman et al. (2004) found both advantages and disadvantages associated with the e-mediator. E-mediation produced more agreements than live mediation, but negotiators still preferred live mediation (Druckman et al., 2004: 504). Similarly, Lin et al. (2011) found positive outcomes for the use of AniMed, the automated animated mediator, compared to situations where there was no mediator help to negotiating parties. Matz and Ebner (2010) discussed the advantages and disadvantages of online conflict resolution simulations relative to face-to-face simulations.

A major advantage of technology use in conflict resolution is that it can be used to create more complex and structured roleplays in trainings, which can eventually help overcome artificiality, randomness, and out-of-context characteristics of traditional faceto-face simulations and role plays. In traditional role plays students may tend to adhere less to their written instructions and thus, the effectiveness of role plays is often left to their motivation, understanding, and improvisation. Technology, on the contrary, can be used to put students into more structured role plays based in more complex and realistic settings. Wilkenfeld et al. testify to this argument and note the various benefits of decision-support systems used in the University of Maryland negotiation simulations (ICONS) as follows: "they help privately organize information, develop prenegotiation strategies, evaluate and propose midnegotiation offers, generate prescriptions, and most importantly aid negotiators in overcoming their cognitive limitations" (2005: 28). This system also served very valuable in ensuring that every participant shares a common understanding of the relative value of different actions and different possible outcomes in the negotiation context (Wilkenfeld et al., 2005: 28).

A significant advantage of technology, and specifically computer games like Global Conflicts and PeaceMaker, or decision support programs like the one used by Wilkenfeld et al. (2005) or 'e-nego-motion' (see Druckman et al., 2011) is that they capture real life complexity while structuring decision-making in a controlled environment. If the role play is especially connected to a real life conflict, such as in our current study on Global Conflicts, the learning experience can be even more powerful as the students will be more attuned to the context. In this respect, Global Conflicts game is a unique teaching tool that allows some of these unexplored issues related to the use of technology in conflict resolution teaching to be studied systematically. It combines the advantages of role play with more structure and allows for systematically tracking and assessing student actions in a conflict setting.

Recently, Gonzalez, Saner, and Eisenberg (2012) and Cuhadar and Kampf (2014) conducted an experimental study with PeaceMaker to find out whether computer games can generate new learning about the Israeli-Palestinian conflict. They found that PeaceMaker was effective in teaching about this conflict. Cuhadar and Kampf's study (2014) shows that computer games can possibly be used as a peace education tool in order to teach young people a 
less stereotypical and less ethnocentric view of the conflict. It is also important in terms of indicating that the game not only contributes to the gaining of knowledge about the narratives of both sides in the conflict, but also contributes to attitude change at least for those who are not direct parties to the conflict (i.e., Turkish and American students). These are crucial findings that indicate new learning about the out-group and also in-group reappraisal as suggested by Pettigrew (1998). Furthermore, attitude change is triggered through behavior change, by asking students to put themselves in the shoes of a person that they normally would not do in real life. An Israeli student has to think and act like the Palestinian President while playing the game, and a Palestinian student has to think and act like the Israeli Prime Minister.

In this study we use a different computer game than PeaceMaker because we wanted to see whether playing two different game scenarios (one conflict firsthand experienced, another distant one not directly experienced) could have an impact on the learning about the conflict and perspective taking. In order to test for this, we had to use two different conflict scenarios within the same game and with the same participants. PeaceMaker is only about the high profile Israeli-Palestinian conflict. PeaceMaker produced positive results for all groups (both parties to the conflict and third parties) in enhancing knowledge about conflict, but it did not produce positive results for enhancing perspective taking for parties to the conflict (perspective taking only developed for third parties). This may be due to the nature of the Israeli-Palestinian conflict and the strength of attitudes of the conflict to the parties. Global Conflicts game, on the other hand, allowed us to use different conflict scenarios with the same participants so that we could control for the Israeli-Palestinian scenario.

\subsection{The global conflicts game}

Global Conflicts is an award-winning educational game developed by Serious Games Interactive in Denmark used for teaching about conflicts, citizenship, geopolitics, and media. The game is consisted of several different scenarios, each putting the player in a different context and requires different skills to be employed. The game allows students to explore and learn about different conflicts throughout the world and about the underlying themes of democracy, human rights, globalization, terrorism, climate change and poverty (For more information about the scenarios see www.globalconflicts.eu).

Besides the Israeli-Palestinian conflict which is a high profile case, the rest of the scenarios in the game are of relatively low profile in the global arena (e.g, Uganda, Rwanda). For this study we selected the Israeli checkpoint scenario related to the IsraeliPalestinian conflict and the Guatemalan civil war scenario. We selected the former because unlike the Guatemalan case it is highly sensitive and very much publicized conflict for Israeli-Jewish and Palestinian students. Since this is a global conflict, we expect that it would also resonate with Guatemalans though not as much as the Guatemalan situation. We selected the Guatemalan scenario because while this was a low profile case for both Israel-Jewish and Palestinian students, it was a high profile case for Guatemalan students.

The game universe has been designed as a compressed Arabic/ Jewish or Guatemalan atmosphere in 3D within a contemporary time frame, touching upon the more essential aspects of these situations. In the game, the player is represented by an avatar of a male or female reporter who arrived to the conflict in order to uncover information about the situation through various sources, which collaborate their chosen story. The scenario in the game is based on the real-life accounts reported to human rights organizations and news agencies by victims and witnesses, as well as various other sources.
In the Israeli-Palestinian scenario, the students play the role of a western reporter whose abilities are being tested during the assignment representing one of the following newspapers: Israeli, Palestinian, or western. They are expected to produce a news report geared to the audience of one of these newspapers based on the interviews they conduct with various characters at the check point. They are responsible for uncovering information through various sources, which they can quote later on in their news report. At the end of the game, they get to choose some of the quotes they collected throughout the interviews including them in the final news report on which they are given evaluation. This game score indicates whether the report is placed in the front pages of the newspaper or in the back ones, whether the quotes reflect important pieces of information about the conflict and whether the quotes well fit the newspaper selected for the assignment.

Those who focus exclusively on pro-Palestinian stories will be able to talk to this side with more ease, while some Israelis might be more apprehensive. They are challenged to keep the work objective while gathering important information to be used in the news report. In the meantime, as the students play the western reporter in Global Conflicts, they experience the developments in the Israeli-Palestinian conflict and learn about the issues that are important to this conflict. The students have to form an opinion based upon their own actions and after meeting characters that represent different attitudes to the conflict despite the fact that they write for a specific newspaper.

The Guatemalan scenario was concerned with an upcoming election in which one of the political candidate was accused of committing significant human rights violations during the civil war. The Guatemalan Civil War ran from 1960 to 1996. It was mostly fought between the government of Guatemala and various leftist rebel groups supported chiefly by ethnic Mayan indigenous people and Ladino peasants, who together make up the rural poor. The government forces of Guatemala have been accused of committing genocide against the Mayan population of Guatemala during the civil war and were condemned for widespread human rights violations against civilians during this period. Up to 200,000 people died or went missing during the war (e.g., Centeno, 2007; Schirmer, 1998).

In the game, there was an attack against the political candidate, which the students were assigned to investigate in the role of a Western journalist. After a lengthy period of gathering information about the background of the civil war in Guatemala, the personal background of the candidate, and the general information about the country, the students engage in an interview with the political candidate. They receive a score at the end depending on how successfully they use the arguments and information they gathered during their previous research in this interview.

\section{Research hypotheses}

Previous studies have suggested that political computer games function as effective tool for knowledge acquisition for young people who serve as direct parties in the conflict as well as for third parties to the conflict (e.g., Cuhadar \& Kampf, 2014; Kampf, 2011, 2014), and therefore we hypothesize:

H1. All participants will acquire knowledge about proximate conflicts after playing games about these scenarios, and there will be insignificant differences between the three national groups.

Studies have indicated that the media are particularly effective in knowledge acquisition about distant events on which previous knowledge is scarce (e.g., Cohen, 2013). Given that the Guatemalan situation is less proximate in the global arena than the Israeli-Palestinian conflict, we expect: 
H2. Israeli-Jews and Palestinians will acquire more knowledge from the Guatemalan game than Guatemalans will acquire from the Israeli-Palestinian game.

Recent studies have pointed out that direct parties to the conflict holding strong attitudes about the situation change their attitudes after they are presented with information about the two sides in the conflict rather than just one of them (e.g., Bar-Tal, Halpern, \& Pliskin, in press; Schori-Eyal, Halperin, \& Bar-Tal, in press). Given that the Israeli-Palestinian scenario in the game presents the hardships of both Israeli soldiers and Palestinian civilians in the checkpoint, while the Guatemalan scenario focuses on the accusations of the political candidate in human right violations during the civil war, we hypothesize:

H3. Israeli-Jews and Palestinians will change their attitude about the Israeli-Palestinian conflict after playing the Israeli-Palestinian game more than Guatemalans will change their attitude about the Guatemalan civil war after playing the Guatemalan game.

Research on attitude strength has suggested that participants hold weak attitudes toward distant events and therefore it is easier for them to take a different perspective in these events after acquiring some knowledge about them (e.g., Eagly \& Chaiken, 1998). Yet given that the Guatemalan civil war is less proximate in the global arena than the Israeli-Palestinian conflict, we expect:

H4. All participants will change their attitudes about distant conflicts after playing games about them, but Israeli-Jews and Palestinians will change their attitudes about the Guatemalan civil war after playing the Guatemalan game more than Guatemalans will change their attitudes about the Israeli-Palestinian conflict after playing the Israeli-Palestinian game.

\section{Method}

\subsection{Participants}

Hundred undergraduate students ranging from sophomores to seniors participated in the study. 40 Israeli-Jewish participants were from Tel Aviv University, 30 Palestinian students were from Al-Quds University and 30 Guatemalan students were from University of San-Carlos of Guatemala.

A Chi-Square test of gender and nationality showed insignificant results $\left(X^{2}=.37, p=n . s\right.$.), indicating that the three groups were equally divided by gender. A one-way ANOVA of nationality as a between-subjects factor and age as a within-subjects factor showed that Israeli-Jewish participants were significantly older $(M=25.09, \quad S D=1.59)$ than Palestinian participants $(M=21.17, S D=1.44)$ and Guatemalan participants $(M=21.08$ $S D=1.45)\left(F(2,98)=101.9, p<.001, \eta^{2}=.19\right)$. This difference is due to the fact that Israelis serve a period of three to four years in the army.

\subsection{Design and procedure}

The study was conducted as part of classes dealing with various aspects of political science and conflict resolution and the students received credit for their participation. The data on students of University of San-Carlos was collected in March 2013, the data on students of Tel Aviv University was collected in April 2013, and the data on students of Al-Quds University was collected in June 2013. Data collection in Guatemala was completed before the trial of Rios Montt, who was the President of Guatemala during the civil war, was widely publicized and completed. Data collection in Israel and Palestine was conducted while this trial was completed but this trial received minor coverage in the news media mainly in the section of international news which receives less attention by young people, so it was unlikely to bias the data collection.

The study took up to three hours and included four parts. First, participants were introduced to the Global Conflicts game and played a short demo. Second, they filled in a short questionnaire. Third, participants played the two scenarios in the game in random order. Finally, after playing the two scenarios the participants again filled in a short questionnaire. The questionnaire used before and after the game was almost identical in content with the exception of a few additional questions in the post-game questionnaire deliberating participants' experience with the game.

\subsection{Measures}

As our measure of knowledge about the Israeli-Palestinian conflict, students were asked a battery of 20 open-ended and closed-ended knowledge questions on various political and historical aspects of the Israeli-Palestinian conflict varying in degrees of difficulty, such as: "Name the parties to the 1993 Oslo agreement"; "Who is covered in the Right of Return"; and "What is the meaning of the Nakba Day". This measure has already been used in previous studies, which examined PeaceMaker's effectiveness regarding knowledge acquisition among participants who are direct parties to the conflict (i.e., Israeli-Jews and Palestinians) and those who are second and third parties (i.e., Turks and Americans) (e.g., Cuhadar \& Kampf, 2014). The coding differentiated between correct answers, do not know answers, and incorrect answers. In order to measure knowledge acquisition we focused on the number of correct answers in the two questionnaires.

As our measure of background knowledge about the Guatemalan civil war, students were asked a battery of 19 open-ended and closed-ended knowledge questions on various political and historical aspects of the civil war in Guatemala varying in degrees of difficulty, such as: "What is impunity"; "Who is URNG"; and "When did the civil war run in Guatemala". These questions were taken from historical and political studies that examined the civil war in Guatemala (e.g., Centeno, 2007; Schirmer, 1998). The coding differentiated between correct answers, do not know answers, and incorrect answers. In order to measure knowledge acquisition we focused on the number of correct answers in the two questionnaires.

In order to assess attitudes in the Israeli-Palestinian conflict, we examined 'how right is each side' on key issues in the conflict including water, refugees, borders, settlements, Jerusalem, and security. The following scale was used in this question: 1 . Palestinians are absolutely right, 2 . Palestinians are somewhat right, 3. Both sides are equally right, 4 . Israelis are somewhat right, and 5. Israelis are absolutely right. After conducting a factor analysis, the average of answers given on the six key issues was used as a measure of attitude change about the conflict before and after playing the game. This measure has already been used in previous studies conducted with PeaceMaker examining attitude change and perspective taking of participants who are direct parties to the Israeli-Palestinian conflict and those who are second and third parties (e.g., Cuhadar \& Kampf, 2014).

We assessed attitudes about the Guatemalan civil war by a series of six statements from the game indicating various angles of the situation. We selected statements that indicated key points in the civil war based on historical and political studies about the situation (e.g., Centeno, 2007; Schirmer, 1998). The participants were required to indicate how much they agree with each statement on a five-point scale in which 1 and 2 indicating agreement with the various leftist rebel groups supported chiefly by ethnic Mayan indigenous people and Ladino peasants, who together make up the rural poor in the civil war and 4 and 5 indicating support of 
the government in this war. The third category indicated "no idea" and we included this category because the Guatemalan scenario is a low profile case for both Israeli-Jewish and Palestinian participants, and they may not have any solid attitude about it before playing the game. After conducting a factor analysis, the average of answers given on the six statements was used as a measure of attitude change in the conflict before and after playing the game.

Political attitudes were measured by the following question: If you were to place yourself on the following scale, where would you locate yourself in political terms? A ten-point scale was used in this question, 1 representing extreme left and 10 representing extreme right. For the purpose of data analysis, this scale was divided into three categories: left, center, and right.

We measured the proximity (i.e. attitude strength) of the Guatemalan and Israeli-Palestinian conflicts for the participants by two questions. The first question examined how much the participant cares about each of the two conflicts. A four-point scale was used in this question, 1 representing uninterested at all and 4 representing very much interested. The second question examined how important and relevant each of the two conflicts to the participant's country. A five-point scale was used in this question, 1 representing not important at all and 5 representing extremely important.

\subsection{Statistical procedures}

We conducted a Repeated Measures ANOVA to test our research hypotheses. We investigated the effect of playing the game on knowledge acquisition and attitude change at two separate time points: pre- and post- game intervention.

\section{Results}

\subsection{Distant vs. proximate scenarios: Interest and relevance}

Using our measures of interest in proximate conflicts (i.e., Israeli-Palestinian conflict for Israeli-Jewish and Palestinian participants and Guatemalan civil war for Guatemalan participants) and interest in distant conflicts (i.e., Israeli-Palestinian conflict for Guatemalan participants and Guatemalan civil war for Israeli-Jewish and Palestinian participants), we conducted a repeated measures ANOVA as interest in proximate and distant conflicts (i.e., interest in proximate conflicts and interest in distant conflicts) as a withinsubject factor and nationality as a between-subjects factor. The interaction between the two factors was insignificant $\left(F(2,98)=2.23\right.$, n.s. $\left.\eta^{2}=.04\right)$. Israeli-Jews, Palestinians and Guatemalans were more interested in proximate conflicts $(M=3.39$ $S D=.49, M=3.3 S D=.48, M=3.8 S D=.41)$ than in distant ones $(M=1.51 S D=.68, M=1.2 S D=.41, M=1.57 S D=.51)(F(1,99)=$ 8.56, $p<.0001 \eta^{2}=.89$ ), but there were insignificant differences between the three national groups (see Table 1 ).

Similarly, using our two measures of relevance of proximate conflicts and relevance of distant conflicts, we conducted a repeated measures ANOVA with relevance of proximate and distant conflicts as a within-subjects factor and nationality as a between-subjects factor. The interaction between the two factors was significant $\left(F(2,98)=4.52, p<.013 . \eta^{2}=.084\right)$. Israeli-Jewish,

Table 1

Interest: proximate vs. distant conflicts.

\begin{tabular}{lll}
\hline & Proximate $M: S D$ & Distant $M: S D$ \\
\hline Israeli-Jews & $3.39: .49$ & $1.51: .68$ \\
Palestinians & $3.33: .47$ & $1.2: .41$ \\
Guatemalans & $3.80: .41$ & $1.57: .51$ \\
\hline
\end{tabular}

Palestinian, and Guatemalan participants perceived proximate conflicts $(M=4.99 S D=.12, M=4.95 S D=.12 M=4.85 S D=.15)$ as more relevant to their countries than distant conflicts $(F(1,99)=$ 1630.77, $\left.p<.0001 . \eta^{2}=.94\right)$. But Guatemalan participants perceived the Israeli-Palestinian conflict as more relevant to their country $(M=2.1 S D=.79)$ than Israeli-Jewish and Palestinian participants perceived the Guatemalan civil war $(M=1.83 S D=.92$, $M=1.4 S D=.62$ ) (see Table 2).

\subsection{Proximate scenarios: knowledge acquisition}

In order to investigate the game effects on knowledge acquisition about proximate conflicts (i.e., Israeli-Palestinian scenario for Israeli-Jewish and Palestinian participants and Guatemalan scenario for Guatemalan participants), we used our measure of knowledge acquisition for proximate scenarios before playing the game which received the total number of correct answers before playing the game for the Israeli-Palestinian conflict in case of Israeli-Jewish and Palestinian participants and the total number of correct answers before playing the game for the Guatemalan conflict in case of Guatemalan participants. A similar measure was used for knowledge acquisition for proximate scenarios after playing the game.

A repeated measures ANOVA was conducted, with knowledge acquisition for proximate scenarios (i.e., before after playing the game) as a within-subjects factor and nationality (Israeli, Guatemalan or Palestinian) as a between-subjects factor. The interaction between the two measures was insignificant, $F(2,98)=.592$, n.s. $\eta^{2}=.012$. To put it differently, though all participants acquired knowledge about proximate scenarios from the game $\left(F(1,99)=196.37, p<.0001, \eta^{2}=.67\right)$, there were insignificant differences between the three national groups with this respect (see Table 3). Israeli-Jews acquired more knowledge after playing the Israeli-Palestinian game than before playing it $(M=16.1$ $S D=2.04 ; \quad M=18.3 S D=1.67)$. Similarly, Palestinians acquired more knowledge after playing the Israeli-Palestinian game than before playing it $(M=15.1 S D=2.14 ; M=17.13 S D=1.63)$. Finally, Guatemalans acquired more knowledge after playing the Guatemalan game than before playing it $(M=15.73 S D=1.04$; $M=17.53 S D=0.63)$.

\subsection{Distant scenarios: knowledge acquisition}

In order to investigate the game effects on knowledge acquisition about distant conflicts (i.e., Israeli-Palestinian scenario for Guatemalan participants and Guatemalan scenario for IsraeliJewish and Palestinian participants), we used our measure of knowledge acquisition for distant scenarios before playing the game which received the total number of correct answers before playing the game for the Guatemalan conflict in case of Israeli-Jewish and Palestinian participants and the total number of correct answers before playing the game for the Israeli-Palestinian conflict in case of Guatemalan participants. A similar measure was used for knowledge acquisition for distant scenarios after playing the game.

A repeated measures ANOVA was conducted, with knowledge acquisition for distant scenarios (i.e., before after playing the game) as a within-subjects factor and nationality (Israeli, Guatemalan or Palestinian) as a between-subjects factor. The interaction between

Table 2

Relevance: proximate vs. distant conflicts.

\begin{tabular}{lll}
\hline & Proximate $M: S D$ & Distant $M: S D$ \\
\hline Israeli-Jews & $4.99: .12$ & $1.83: .92$ \\
Palestinians & $4.95: .12$ & $1.4: .62$ \\
Guatemalans & $4.85: .15$ & $2.1: .79$ \\
\hline
\end{tabular}


Table 3

Knowledge acquisition about proximate scenarios.

\begin{tabular}{lll}
\hline & Before playing the game $M: S D$ & After playing the game $M: S D$ \\
\hline Israeli-Jews & $16.1: 2.04$ & $18.3: 1.67$ \\
Palestinians & $15.1: 2.14$ & $17.13: 1.63$ \\
Guatemalans & $15.73: 1.04$ & $17.53: 0.63$ \\
\hline
\end{tabular}

the two measures was significant, $F(2,98)=141.54, p<.0001$ $\eta^{2}=.743$. All participants acquired knowledge about distant scenarios from the game $\left(F(1,99)=167.39, p<.0001, \eta^{2}=.941\right)$. Guatemalans held more knowledge about the Israeli-Palestinian conflict before playing the game $(M=9.8, S D=1.7)$ than IsraeliJews $(M=1.5, S D=1.1)$ and Palestinians $(M=.53 S D=.21)$ about the Guatemalan scenario. After playing the game, Israeli-Jewish $(M=13.1, S D=2.9)$ and Palestinian $(M=14.5 S D=2.3)$ participants acquired more knowledge about the Guatemalan scenario than Guatemalan participants acquired $(M=12.1 S D=1.06)$ about the Israeli-Palestinian scenario (see Table 4).

\subsection{Proximate scenarios: attitude change}

In order to investigate the game effects on attitude change about proximate scenarios (i.e., Israeli-Palestinian scenario for Israeli-Jewish and Palestinian participants and Guatemalan scenario for Guatemalan participants), we used our measure of attitudes in proximate scenarios before playing the game which received the average of answers given on the six key issues with regard to the Israeli-Palestinian conflict before playing the game in case of Israeli-Jewish and Palestinian participants and the average of answers given on the six statements with regard to the Guatemalan conflict before playing the game in case of Guatemalan participants. A similar measure was used for attitudes in proximate scenarios after playing the game.

A repeated measures ANOVA was conducted, with attitudes in proximate scenarios (i.e., before after playing the game) as a within-subjects factor, nationality (Israeli, Guatemalan or Palestinian) as a between-subjects factor and political attitudes as covariate. The interaction between attitudes in proximate issues and political ideology was insignificant. The interaction between attitudes in proximate scenarios and nationality was significant, $F(2,98)=3.88$, $p<.05 \eta^{2}=.073$. Israeli-Jews held a more pro-Israeli view before playing the Israeli-Palestinian game $(M=3.88 S D=.59)$ and got closer to thinking that both Israeli and Palestinian sides were equally right regarding key issues in the conflict after playing the game $(M=3.35 S D=.66)$. Palestinians held a very pro-Palestinian view before playing the Israeli-Palestinian game $(M=1.07 S D=.09)$ and got closer to thinking that both sides are equally right after playing the game though still held a more pro-Palestinian view $(M=2.03$ $S D=.11$ ). Guatemalans held a very pro-Mayan view before playing the Guatemalan game $(M=1.41 S D=.226)$ and did not change their attitude after playing it $(M=1.51 S D=.23)$ (see Table 5).

\subsection{Distant scenarios: attitude change}

In order to investigate the game effects on attitude change about distant scenarios (i.e., Israeli-Palestinian scenario for Guatemalan participants and Guatemalan scenario for Israeli-Jewish and

\section{Table 4}

Knowledge acquisition about distant scenarios.

\begin{tabular}{lll}
\hline & Before playing the game $M: S D$ & After playing the game $M: S D$ \\
\hline Israeli-Jews & $1.5: 1.1$ & $13.1: 2.9$ \\
Palestinians & $.53: .21$ & $14.5: 2.3$ \\
Guatemalans & $9.8: 1.7$ & $12.1: 1.1$ \\
\hline
\end{tabular}

Table 5

Attitude change about proximate scenarios.

\begin{tabular}{lll}
\hline & Before playing the game $M: S D$ & After playing the game $M: S D$ \\
\hline Israeli-Jews & $3.88: .59$ & $3.35: .66$ \\
Palestinians & $1.07: .09$ & $2.03: .11$ \\
Guatemalans & $1.41: .26$ & $1.51: .23$ \\
\hline
\end{tabular}

Table 6

Attitude change about distant scenarios.

\begin{tabular}{lll}
\hline & Before playing the game $M: S D$ & After playing the game $M: S D$ \\
\hline Israeli-Jews & $2.98: .12$ & $1.93: .49$ \\
Palestinians & $3.04: .54$ & $1.26: .13$ \\
Guatemalans & $2.06: .53$ & $2.82: .28$ \\
\hline
\end{tabular}

Palestinian participants), we used our measure of attitudes in distant scenarios before playing the game which received the average of answers given on the six key issues with regard to the Israeli-Palestinian conflict before playing the game in case of Guatemalans and the average of answers given on the six statements with regard to the Guatemalan scenario in case of Israeli-Jewish and Palestinian participants. A similar measure was used for attitudes in distant scenarios after playing the game.

A repeated measures ANOVA was conducted, with attitudes in distant scenarios (i.e., before after playing the game) as a withinsubjects factor, nationality (Israeli, Guatemalan or Palestinian) as a between-subjects factor and political ideology as covariate. The interaction between attitudes in distant scenarios and political ideology was insignificant. The interaction between attitudes in distant scenarios and nationality was significant, $F(2,98)=214.48$, $p<.0001 \eta^{2}=.816$. All participants changed their attitudes after playing the game $\left(F(1,99)=23.99, p<.0001 \eta^{2}=.19\right)$. Both IsraeliJews and Palestinians did not have any solid view about the Guatemalan civil war before playing the game $(M=2.98 S D=.12$; $M=3.04 S D=.54$ respectively). After the game they got closer to hold a more pro-Mayan view $(M=1.93 S D=.49 ; \quad M=1.26$ $S D=.13)$. The Guatemalans held a pro-Palestinian view with regard to the Israeli-Palestinian conflict before playing the Israeli-Palestinian game, and after the game they got closer to thinking that both Israelis and Palestinians are equally right with regard to the situation $(M=2.06 S D=.532 ; M=2.82 S D=.286)$ (see Table 6).

\section{Discussion and conclusions}

Games like Global Conflicts are emerging as a new medium for peace education. However, few empirical studies, to our knowledge, have been conducted to evaluate how effective computer games are as a peace education tool, particularly comparing games about different conflictual contexts as this study does (e.g., Cuhadar \& Kampf, 2014; Kampf, 2011, 2014). To test whether Global Conflicts is useful as a peace education tool, this study was conducted to evaluate how effective this game is in enhancing knowledge and contributing to attitude change and perspective taking, comparing distant and proximate conflictual contexts. This study is important in that it is among the first to provide empirical evidence that interactive digital games like Global Conflicts are effective as a peace education tool. Previous studies have already indicated Global Conflict's effectiveness as a pedagogical tool in teaching conflict assessment and resolution (e.g., Buch \& Egenfeldt-Nielsen, 2007; Raphael, Bachen, \& Hernández-Ramos, 2012). Yet these studies used post-game self-reports and game score as measures of learning outcomes, while the current study uses pre- and post-game direct measures for this purpose (i.e., background knowledge and attitudes). 
When we revisit our hypotheses in line with the results presented, our first hypothesis is supported as all participants acquired new knowledge about the conflict that is proximate to them after playing the game about that scenario. For both IsraeliJewish, Palestinian, and Guatemalan students their knowledge about their own conflict increased.

Our second hypothesis is also supported as Israeli-Jews and Palestinians acquired more knowledge about the Guatemalan conflict, than Guatemalans acquired about the Israeli-Palestinian conflict. This was expected because the Israeli-Palestinian conflict is a world-known and salient conflict that occupies a great deal of space in the world news as opposed to the Guatemalan conflict. Therefore, Guatemalan students had more knowledge about the Israeli-Palestinian conflict prior to playing the scenarios than Israeli-Jews and Palestinians had about the Guatemalan situation.

Our study found promising results with regard to attitude change and perspective taking as well. Our third hypothesis stating that Israeli-Jews and Palestinians will change their attitude about the Israeli-Palestinian conflict after playing the Israeli-Palestinian game more than Guatemalans will change their attitude about the Guatemalan civil war after playing the Guatemalan game has been supported. Both Israeli-Jewish and Palestinian students took the perspective of the "other" side after playing the Israeli-Palestinian game and shifted from ethnocentric attitudes towards a more impartial attitude. However, the same effect was not obtained for the Guatemalan students. This is most likely due to the different natures of the two scenarios used in the game. The Guatemalan conflict is about social justice and massive human rights violations towards the Mayan people, whereas the checkpoint scenario introduces the narrative emphasizing the hardships experienced by both sides in the conflict. Still, it is very important to note that the game has changed the attitude of Israeli-Jewish and Palestinian participants about a conflict they have strong attitudes about in the beginning.

Finally, hypothesis four is supported. All participants changed their attitudes about distant conflicts after playing the two scenarios. Both Israeli-Jews and Palestinians did not have any solid view about the Guatemalan civil war before playing the game, but after the game they got closer to hold a more pro-Mayan view. The Guatemalans held a more pro-Palestinian view with regard to the Israeli-Palestinian conflict before playing the Israeli-Palestinian game, and after the game they got closer to thinking that both Israelis and Palestinians are equally right with regard to the situation. Israeli-Jewish and Palestinian participants held weak attitudes toward the Guatemalan situation before playing the game and therefore the game changed their attitudes about the situation. In comparison, Guatemalans held a more solid attitude toward the Israeli-Palestinian conflict before playing the game because this conflict is well-known in the global arena and quite relevant to their country (as shown in their questionnaire answers about its relevance). Despite that, because the game presents the hardships of Israeli soldiers and Palestinian people in the checkpoints, it helped the Guatemalans to develop a more impartial attitude toward the situation.

In sum, the game was successful in increasing knowledge and changing attitudes for both conflicts that the participants related to personally and conflicts that were more distant. There are variations between scenarios, especially due to the different nature of the conflicts, but it is promising to see that the game was effective in generating perspective taking for Israeli-Jewish and Palestinian students with regard to their own conflict. This is incongruous with the findings from Cuhadar and Kampf (2014) study on PeaceMaker where attitude change and perspective taking was identified only for those who were not direct parties to the conflict (i.e., Turks and Americans). Two possible explanations can be suggested to the different learning outcomes of the two games which require further studies in the future because this study did not compare these games or analyzed game characteristics. First, PeaceMaker focuses on the perspective of the Israeli-Prime Minister and the Palestinian President to the Middle Eastern situation, while Global Conflicts focuses on the perspective of Israeli soldiers and Palestinian people in the checkpoint. The latter is a more personal and human perspective on the situation than the former and therefore Israeli and Palestinian participants, particularly young ones, may find it easier to identify and empathize with. In addition, Global Conflicts may be a more immersive game environment than PeaceMaker. The immersion effect creates an environment in which the players submerge themselves and progressively increase their attention and concentration in this environment resulting in more positive effects on memory retention, attitude change and knowledge acquisition (Raphael et al., 2012; Yan \& Cordry, 2011).

Based on our findings, we can say that computer games like Global Conflicts can serve as an effective tool for peace education for two key considerations which require another study in the future. First, these games are uniquely suited to illustrate complex issues such as the Israeli-Palestinian conflict or the Guatemalan civil war in a very engaging and interactive way, compared to other more passive and linear media (e.g., Gee, 2008). In this sense, they facilitate the participants' gaining of a conceptually complex view of the conflict as opposed to the simplistic and polarized view of the conflict often presented in collective narratives and mainstream socialization agents in a conflict environment. Achieving this, computer games can thus be a tool, as indicated by peace education scholars, for legitimating the other's narrative in a way that events are seen from both perspectives. This is an important step towards increasing learning about the "out-group" and the conflict dynamics as indicated by social and political psychologists working on inter-group conflict; a necessary step towards attitude change and reducing inter-group tensions.

Second, by facilitating role-taking from both sides, Global Conflicts intends to provide a unique opportunity to inform people of the issues in the conflict and influence their attitudes toward the other side. In games like Global Conflicts, we can differentiate between basic learning in the game, aiming at acquiring knowledge and collecting data, and deeper learning beyond the game aiming at changing the players' perspectives regarding the situation (Mitgutch, 2011). In fact, previous studies have indicated that playing a game eliciting role-taking resulted in greater knowledge acquisition and greater attitude change than reading a text conveying the same information (e.g., Bogost, 2007; Peng, Lee, \& Heeter, 2010).

This is in the direction of another goal articulated by peace education scholars: liberating the parties from a perception of "sole victimhood" in the conflict. The more they can understand and appreciate the perspective of the other party in the conflict, the more likely that empathy will develop and they will step out of a "victim" mentality. This may also lead to "in-group reappraisal" where parties begin to critically assess their group's contribution to the conflict dynamics. Computer games and their effects in this regard should be further explored in depth in future research.

The results measuring the effectiveness of the Global Conflicts game are promising in terms of showing that computer games can be used as part of peace education trainings. Our results indicate that they are not only useful in teaching a more complex view of the conflict to the parties, particularly to those who are direct parties to the conflict with strong attitudes on the issues, but also in engendering attitude change especially in the form of taking a more balanced perspective and being able to look at the conflict from both lenses. However, it is also important to note the different results obtained from the Israeli-Palestinian vs. the Guatemalan scenarios. The framing of the story is crucial (i.e., a troubled checkpoint where the Israeli soldiers and Palestinian civilians are 
both stressed about their security as opposed to a political candidate who is clearly an oppressor who conducted massive human rights abuses toward the poor and weak people)in determining whether the players will gain the perspective of both sides or not.

Given that Guatemalan young people participating in this study have become young adults long after the civil war ended, this study is especially promising for young Israeli and Palestinian people for whom the Israeli-Palestinian conflict is a daily ongoing situation. Previous studies have already shown that Israeli and Palestinian young people know almost nothing about what transpires on the other side of the Israeli-Palestinian divide, except for the limited and violent images constructed by the media and daily incidents (e.g., Wolfsfeld, Frosh, \& Awabdy, 2008). Moreover, since these young people have never actually experienced a state of peace they may not regard it as a significant value for which a price should be paid. Therefore, the opportunity for young Israeli and Palestinian people to learn about the "other", even through computer games like Global Conflicts, and to perhaps understand him, is an issue of great importance in any process of reconciliation in the Middle East and an essential requirement for obtaining public support and legitimacy for the peace initiative.

\section{References}

Anderson, M. B., Chigas, D., \& Woodrow, P. (2007). Encouraging effective evaluation of conflict prevention and peacebuilding activities: Towards DAC guidance. Paris: OECD-DAC, 23. Available at www.oecd.org/dataoecd/52/3/39660852.pdf. Accessed 09.09.14.

Bar-Tal, D. (1997). Formation and change of ethnic and national stereotypes: An integrative model. International Journal of Intercultural Relations, 21, 491-523.

Bar-Tal, D. (2013). Intractable conflicts: Socio-psychological foundations and dynamics. New York, NY: Cambridge University Press.

Bar-Tal, D., Halpern, E., \& Pliskin, R. (in press). Why it is so difficult to resolve intractable conflicts peacefully? A socio-psychological explanation. In M Galluccio (Ed.), Handbook of international negotiation: Interpersonal intercultural and diplomatic perspective. New York: Springer.

Bhappu, A., Ebner, N., Kaufman, S., \& Welsh, N. (2009). The strategic use of online communication technology to facilitate relational development in executive training courses on negotiation. In C. Honeyman, J. Coben, \& G. DePalo (Eds.), Second generation negotiation teaching. DRI Press.

Bogost, I. (2007). Persuasive games. Cambridge: MIT Press.

Brown, S., Boyer, M., Mayall, H., Johnson, P., Meng, L., Butler, M., et al. (2003). The GlobalEd project: Gender differences in a problem-based learning environment of international negotiations. Instructional Science, 31, 255-276.

Buch, T., \& Egenfeldt-Nielsen, S. 2007. The learning effects of Global Conflicts Media@Terra, Athens.

Burak, A., Keylor, E., \& Sweeney, T. (2005). PeaceMaker: A video game to teach peace. In Intelligent technologies for interactive entertainment (pp. 307-310). Berlin: Springer.

Centeno, M. (2007). Warfare in Latin America. Ashgate.

Chalamish, M., \& Kraus, S. (2012). AutoMed: An automated mediator for multi-issue bilateral negotiations. Autonomous Agents and Multi-Agent Systems, 24(3), $536-564$.

Cohen, A. A. (Ed.). (2013). Foreign news on television: Where in the world is the global village? New York: Peter Lang.

Coleman, P. (2000). Intractable conflict. In M. Deutch \& P. Coleman (Eds.), The Handbook of conflict resolution. San Francisco: Jossey Bass Publishers.

Cuhadar, E., \& Dayton, B. (2011). The social psychology of identity and intergroup conflict: From theory to practice. International Studies Perspectives, 12, 273-293.

Cuhadar, E., \& Kampf, R. (2014). Learning about conflict and negotiations through computer simulations: The case of PeaceMaker. International Studies Perspectives, $15,142-162$.

Druckman, D., Dannenman, D., Filzmoser, M., Gettinger, J., Koeszegi, S., Mitterhofer, R., et al. (2011). e-nego-motion: Integration of behavioral and decision support in e-negotiations. In Proceedings of the 24th annual international association for conflict management (IACM). Turkey: Istanbul.

Druckman, D., Druckman, J., \& Arai, T. (2004). E-Mediation: Evaluating the impacts of an electronic mediator on negotiating behavior. Group Decision and Negotiation, 13, 481-511.

Eagly, A., \& Chaiken, S. (1998). Attitude structure and function. In D. T. Gilbert, S. T. Fiske, \& G. Lindzey (Eds.), The handbook of social psychology. New York: McGraw-Hill.

Ebner, N. (2008). Online dispute resolution: Applications for e-HRM". In T. TorresCoronas \& M. Arias-Oliva (Eds.), Encyclopedia of human resources information systems: Challenges in e-HRM. Hershey, PA: Idea Group Reference Publishing.
Fisher, R. (1997). Interactive conflict resolution. Syracuse, NY: Syracuse University Press.

Fisher, R. (2005). Paving the way: Contributions of interactive conflict resolution to peacemaking. Lanham, MD: Lexington Books.

Galin, A., Gross, M. \& Gosalker, G. (2007). E-negotiation versus face-to-face negotiation what has changed-if anything? Computers in Human Behavior, 23, $787-797$.

Gee, J. P. (2008). Learning and games. In K. Salen (Ed.), The ecology of games: Connecting youth, games, and learning (pp. 21-40). Cambridge, MA: MIT Press.

Gehlbach, H., Brown, S., Ioannou, A., Boyer, M., Hudson, N., Niv-solomon, A., et al. (2008). Increasing interest in social studies: Social perspective taking and selfefficacy in stimulating simulations. Contemporary Educational Psychology, 33(4), 894-914.

Gonzalez, C., Saner, L. D., \& Eisenberg, L. (2012). Learning to stand in the other's shoes: A Computer video game experience of the Israeli-Palestinian conflict. Social Science Computer Review, 31(2), 236-243.

Hadjipavlou, M. (2007). Multiple realities and the role of peace education in deeprooted conflicts: The case of Cyprus. In Z. Bekerman \& C. McGlynn (Eds.), Addressing ethnic conflict through peace education. New York: Palgrave MacMillan.

Hannafin, M., \& Kim, M. (2003). In search of a future: A critical analysis of research on web based teaching and learning. Instructional Science, 31, 347-351.

Hewstone, M., \& Greenland, K. (2000). Inter-group conflict. International Journal of Psychology, 35, 136-144

Kampf, R. (2011). Internet, conflict and dialogue: The Israeli case. Special issue of Israel Affairs on New Media, Politics and Society in Israel. In Gideon Doron \& Azi Lev-On, 17(3), 384-400.

Kampf, R. (2014). Are two better than one? Playing singly, playing in dyads in a computerized simulation of the Israeli-Palestinian Conflict. Computers in Human Behavior, 32, 9-14.

Kelman, H. (1995). Contributions of an unofficial conflict resolution effort to the Israeli-Palestinian breakthrough. Negotiation Journal, 11, 19-27.

Kelman, H. (1997). Social-psychological dimensions of international conflict. In W. Zartman \& L. Rasmussen (Eds.), Peacemaking in international conflict. Washington, DC: USIP Press.

Kriesberg, L., Northrup, T., \& Thorson, S. (Eds.). (1989). Intractable conflicts and their transformation. Syracuse, NY: Syracuse University Press.

Lawless, K., \& Brown, S. (2003). From digital road to educational expressway: Innovations in web-based pedagogy. Instructional Science, 31, 227-230.

Lin, R., Gev, Y., \& Kraus, S. (2011). Bridging the gap: Face-to-face negotiations with automated Mediator. IEEE Intelligent Systems, 26(6), 40-47.

Malhotra, D., \& Liyanage, S. (2005). Long-term effects of peace workshops in protracted conflicts. Journal of Conflict Resolution, 49(6), 908-924.

Maoz, I. (2000). An experiment in peace: Reconciliation-aimed workshops of Jewish-Israeli and Palestinian youth. Journal of Peace Research, 37(6), 721-736.

Maoz, I. (2004). Coexistence is in the eye of the beholder: Evaluating intergroup encounter interventions between Jews and Arabs in Israel". Journal of Social Issues, 60(2), 437-452.

Maoz, I., \& Bar-On, D. (2002). From working through the holocaust to current ethnic conflicts: Evaluating the TRT group workshop in Hamburg. Group, 26, 29-48.

Matz, D. \& Ebner, N. (2010). Using role play in online negotiation teaching. In C Honeyman, J. Coben, \& G. De Palo (Eds.), Venturing beyond the classroom. St. Paul, MN: DRI Press.

Mitgutsch, K. (2011). Serious learning in serious games: Learning in, through and beyond serious games. In M. Ma et al. (Eds.), Serious games and edutainment applications (pp. 45-58). Springer Science+Buisness Media.

Peng, W., Lee, M., \& Heeter, C. (2010). The effects of a serious game on role-taking and willingness to help. Journal of Communication, 60(4), 723-742.

Pettigrew, T. (1998). Inter-group contact theory. Annual Review of Psychology, 49, $65-85$.

Pettigrew, T. (1986). The inter-group contact hypothesis reconsidered. In M. Hewstone \& R. Brown (Eds.), Contact and conflict in inter-group encounters. Oxford: Basil Blackwell.

Raphael, C., Bachen, C. M., \& Hernández-Ramos, P. F. (2012). Flow and cooperative learning in civic game play. New Media \& Society, 14(8), 1321-1338.

Salomon, G. (2002). The nature of peace education: Not all programs are created equal. In G. Salomon \& B. Nevo (Eds.), Peace education, the concept, principles, and practice around the world. London: Erlbaum Associates Publishers.

Saunders, H. (1999). A public peace process. New York: St. Martin's Press.

Schirmer, J. (1998). The Guatemalan military project: A violence called democracy. UPenn Press.

Schori-Eyal, N., Halperin, E., \& Bar-Tal, D. (in press). Three layers of collective victimhood: Effects of multileveled victimhood on intergroup conflicts in the Israeli-Arab context. Journal of Applied Social Psychology.

Wilkenfeld, J., Young, K., Queen, D., \& Assal, V. (2005). Mediating international crises. Oxford: Routledge.

Wolfsfeld, G., Frosh, P., \& Awabdy, M. (2008). Covering death in conflicts: Coverage of the Second Intifada on Israeli and Palestinian television. Journal of Peace Research, 45, 401-417.

Yan, C., \& Cordry, J. (2011). Increased game immersion by using life player-mapped avatar evolution. In M. Chang et al. (Eds.), Edutainment (pp. 276-280). Berlin, Heidelberg: Springer-Verlag. 